\title{
Professional-oriented practical training - a factor in the development of integration of education and production
}

\author{
S.J.Bazarova ${ }^{1}$, F.Kh.Baychayev ${ }^{2}$, \\ ${ }^{1}$ Doctor of Science in Pedagogue, prof. Head of the Department of quality control of education of Navoi State \\ Mining Institute \\ ${ }^{2}$ Assistant of the Department" General Physics", Navoi State Mining Institute
}

\begin{abstract}
The positive results of improving the educational process in higher technical educational institutions on the basis of professional orientation, taking into account the requirements and needs of customer enterprises, are considered.

Keywords: integration, education, production, natural sciences, professional competence, professionally oriented tasks, method, future specialist, mining and metallurgical industry.
\end{abstract}

\section{INTRODUCTION}

Today, when the process of qualitative renewal is taking place in all layers of our society, the education system is reaching a new level in the history of its development, special attention is paid to the creation of an integrated flexible system of continuing education, and the integration of education and production is recognized as one of the priorities of state policy. It is no coincidence that the President stressed that "increasing competition in the context of globalization requires the development and implementation of a completely new approach and principles for a more stable and dynamic development of our country."

The peculiarity of technical universities is that the professional activity of future specialists is directly aimed at solving complex problems using constantly improving methods and technologies, producing products that are competitive in the domestic and foreign markets. Therefore, the paradigm of higher technical education is radically different: it requires flexible adaptation of the goal, content, and management principles to a constantly updated production system.

Successful implementation of reforms in the field of education in a society with developing science and technology requires organizing ways to improve the educational process in technical universities, adapting the content, forms and methods of training to international standards. Today, there is a discrepancy between the requirements for future specialists and the practical professional knowledge and skills of novice professionals. Incomplete development of pedagogical conditions, mechanisms, methods and technologies for the formation of a specialist, insufficient integration of education and production in the development of professional competencies of students, incomplete integration of theory and practice make us think about the integration of training and development.

According to the system of formation of the system of training highly qualified personnel, natural Sciences, which were previously considered only fundamental science, are now recognized as one of the core links necessary for in-depth study of special Sciences. Thus, it has been proven that explaining each topic in terms of specialization, level of application in production, and presenting questions related to the field can lead to positive results.

It is known that physics as a fundamental science is the basis of technology. The future specialist should not only be familiar with physical phenomena and laws, but also be well aware of how important they are in the field in which he is engaged. To this end, one of the initial steps in improving the professional competence of future specialists is to address issues that provide a link between theory and practice in practical physics classes.

An important element of practical training is the proposed training task (problem problem) that needs to be solved. When selecting examples (tasks and logical tasks) for practical classes, the teacher should have a clear idea of the didactic goal - what skills and competencies are acquired as a result of solving each task, what diligence is required from students, what will be the competence of students in solving problems, the key criterion should be the task of identifying their abilities.

Analysis of the methodology for solving problems in physics shows that the algorithm for solving problems in all sections of physics has common and distinctive specific features of each section.

We have conditionally divided the following three stages as a series of algorithms for solving problems in practical classes:

Stage I: Each problem is based on a specific case of physical laws, so before solving problems, it is recommended to study the physical theory of a particular section that includes these problems in depth;

Stage II: solving the problem begins with reading it carefully several times and understanding its contents. When you read the problem conditions, you should not immediately focus on the amount you are looking for and not try to find it quickly. On the contrary, to better understand the physical phenomena reflected in the problem, it is necessary to recall the physical laws and formulas underlying this phenomenon. If you need to find a physical quantity or calculate a chain, you need to determine which values are given in the problem, as well as hidden conditions and quantities that need to be found; 
Stage III: if a drawing or diagram is given in the task, it should be carefully studied. If there is no drawing or diagram in the problem, the student should draw a diagram that fully reflects its content, considering the physical process from the point of view of the problem.

Based on the above ideas and reflections, it was proved that the development and discussion with students in practical classes of issues related to physical phenomena in technological processes used in the mining and metallurgical industry are important for improving the competence of future specialists. Solving career guidance issues in practice not only leads to an in-depth study of science, but also forms students ' initial skills for conducting research in the field of mining and metallurgy. This will create an opportunity to improve the effectiveness of training.

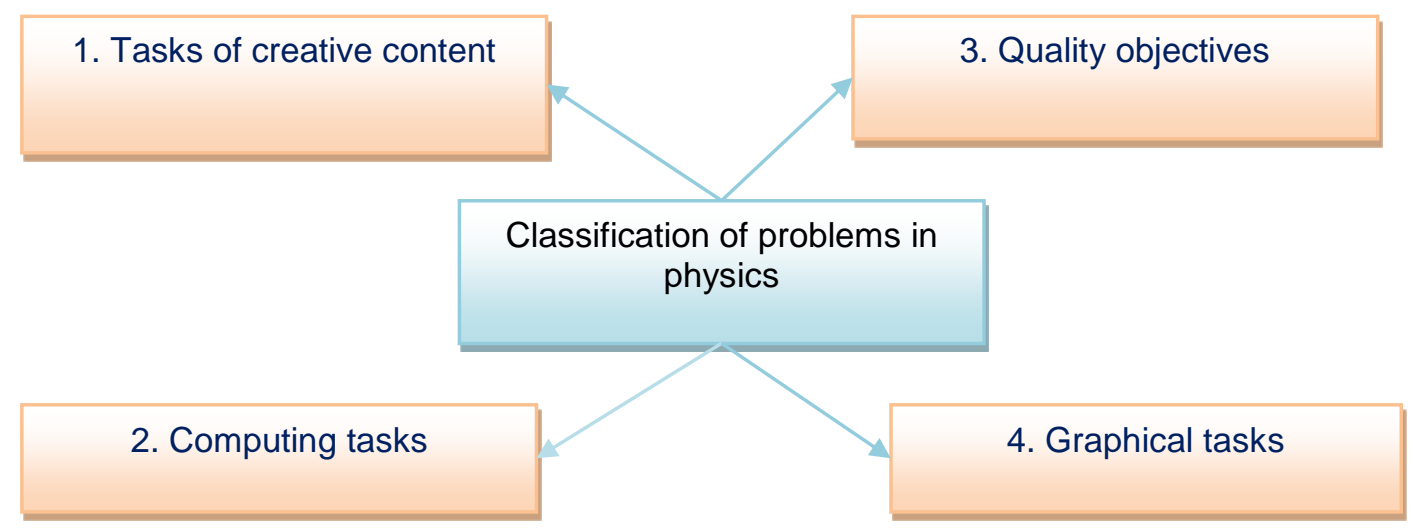

Figure 1.

Focusing on problem classification when developing problem-oriented problems in physics is a tool that provides a variety of problems. This will help future specialists to demonstrate their capabilities on a large scale and come to a solution in different situations. For clarity, figure 1 shows the classification of tasks using the cluster (network) method.

1) Tasks of creative content are considered tasks for which the solution algorithm is unknown. The conditions of such problems will be masked: the data will be insufficient or there will be excessive values, sometimes physical data from the sphere necessary for solving the problem is not provided. When solving creative problems in physics, the first step is to explain the phenomenon, that is, to answer the question why. The second stage provides an answer to the question of how to implement events that meet the requirements, that is, how to do it. For example,

1. How is the density of the resulting rock in the Deposit?

2. Can the miner to measure the pressure in the thermometer?

3. How can I determine the weight of a BelAZ truck carrying ore, depending on the pressure it exerts on the ground, without weighing it on a scale?

4. How to determine the coefficient of friction between the stone moving up the conveyor belt and tape?

2) Computational problems are one of the most effective ways to link theory with practice. A characteristic feature of such problems is that when solving them, physical laws and formulas are directly used, and if not, then new expressions are derived from them. Students become more active and independent in solving computational problems. Because they get the information they need to solve the problem from the technical literature and get results and conclusions faster. For example,

1. At what angle should the ore be thrown at a speed of $20 \mathrm{~m} / \mathrm{s}$, so that the flight distance is 4 times the height of the climb? Find the radius of curvature at the highest point of the trajectory.

2. The driver of BelAZ, moving in the mine depth $\mathrm{h} 1$, found that the barometer in the cab always shows the same pressure $\mathrm{P}=79 \mathrm{kPa}$. When he finished work and went outside, the air temperature changed from $\mathrm{t} 1=5^{\circ} \mathrm{C}$ to $\mathrm{t} 2=1^{\circ} \mathrm{C}$. How high $\Delta \mathrm{h}$ did the driver get out of the mine? Assume that the surface pressure $\mathrm{P}_{0}$ is equal to the normal atmospheric pressure.

3. Find the value of the force acting on the ore weighing $50 \mathrm{~g}$ at a speed of $0.2 \mathrm{~Hz}$ electromagnetic separator

3) Based on physical laws and formulas, the problem is solved by logical thinking. Qualitative questions clearly explain to students physical phenomena and their regularities, teach them to apply theoretical knowledge in practice. In practical classes, quality issues are given in order to consolidate the topic. For example,

1. Why are the tires of quarry cars created wide?

2. Why is the conveyor Belt made of rubber?

3. Why should a BelAZ dump truck carrying ore in a quarry not move at high speed? and falls?

4. Why do cracks form in rocks? How does the distance between molecules change as the temperature rises

4) Problems in graphical form are just a graph of the relationship between two physical quantities. the graph is sometimes set in the conditions of the problem, in some cases it is necessary to build graphs based on the results 
obtained based on the condition of the problem.

The algorithm for solving problems in graphical form is as follows: if you are given a graph of the relationship between physical quantities, you must carefully understand the graph and study the nature of the relationship in one or another part. Using the scale on the graph, you need to find the values of the desired values along the abscissa and ordinate axes. example,

In the process of solving problems in graphic form, students deeply master the basics of physics. For

1. Based on the equation of motion $S=15 t+2 t^{2}$ of the BelAZ-540A mining and lifting machine in the quarry, find the equation of its speed versus time?

2. The dependence of the speed of the rectilinear movement of the mining machine on time is given by the equation $v=2-6 t+12 t^{2}$. If at the initial moment the car was at the origin, find the equation for the time dependence on the distance traveled.

3. The coordinate of a freight car is given by the time dependence equation $x=100+4 t-3 t^{2}$. Find the distance traveled, speed and acceleration at the initial moment of movement of the car.

Research results have shown that creating a system of such professionally-oriented physical tasks for each section of physics, conducting practical classes improves the quality of the educational process and leads to the following positive results:

- leads to the formation of basic skills and competencies in this field, as well as to the growth of creative abilities and professional competence of future specialists;

- acquired creative abilities lead to the development of independent work skills.

Thus, professionally-oriented practical training plays an important role in the development of integration of education and production.

\section{REFERENCES:}

1. Mirziyoyev Sh. On the Strategy of actions for further development of the Republic of Uzbekistan. Decree of the President of the Republic of Uzbekistan No. up-4947 dated February 7, 2017 ttps://lex.uz/ru/docs/3107042

2. Bazarova S. J., Khaletskaya O. Unity of theory and practice: connection of education with production. // "Mountain Bulletin of Uzbekistan". - Navoi, 2003. No. 3. -Pp. 75-78

3. Bazarova S. J. System justification of training technology in technical universities. // Materials of the Republican scientific and technical conference "Istiqlol" (with international participation) "Modern equipment and technology of the mining and metallurgical industry and ways of their development. Navoi. 2006, pp.161-164. 